\title{
A Tyrosine-Dependent Riboswitch Controls the Expression of a Tyrosyl-tRNA Synthetase from Acidithiobacillus ferrooxidans
}

\author{
Paula Bustamante, ${ }^{1,2, *}$ Oriana Salazar, ${ }^{3}$ Héctor Garcías-Papayani, ${ }^{1}$ Pamela Alamos, ${ }^{1}$ Omar Orellana ${ }^{1}$
}

\footnotetext{
1 Program of Cellular and Molecular Biology, Institute of Biomedical Sciences, Faculty of Medicine, University of Chile, Santiago, 8380453, Chile

2 Centre for Infectious Diseases and Microbiology, The Westmead Institute for Medical Research, The University of Sydney, Westmead, NSW, 2145, Australia

3 Centre for Biochemical Engineering and Biotechnology, Department of Chemical Engineering and Biotechnology, Faculty of Physical Sciences and Mathematics, University of Chile, Santiago, Chile

* Corresponding author's e-mail address: paulac_ba@yahoo.com
}

RECEIVED: January 25, 2016 * REVISED: June 14, 2016 * ACCEPTED: June 14, 2016

THIS PAPER IS DEDICATED TO THE LOVING MEMORY OF IVANA WEYGAND-ĐURAŠEVIĆ (1952 - 2014)

\begin{abstract}
Expression of aminoacyl-tRNA synthetases is regulated by a variety of mechanisms at the level of transcription or translation. A T-box dependent transcription termination/antitermination riboswitch system that responds to charged/uncharged tRNA regulates expression of aminoacyl tRNA synthetase genes in Gram-positive bacteria. TyrZ, the gene encoding tyrosyl-tRNA synthetase from Acidithiobacillus ferrooxidans, a Gram-negative acidophilic bacterium that participates in bioleaching of minerals, resembles the gene from Bacillus subtilis including the $5^{\prime}$-untranslated region encoding the riboswitch. Transcription of $A$. ferrooxidans tyr $Z$ is induced by the presence of tyrosine by a mechanism involving antitermination of transcription. This mechanism is probably adapted to the low supply of amino acids of acidic environments of autotrophic bioleaching microorganisms.
\end{abstract}

Keywords: riboswitch, T-box, TyrRS, acidophilic bacterium, tyrosine.

\section{INTRODUCTION}

A MINOACYL-tRNA synthetases (aaRSs) are key enzymes to ensure the translation fidelity of the genetic information into proteins. These enzymes catalyze the first step of protein synthesis through the esterification of amino acids to the 3 '-end of their cognate tRNA species. Although they perform the same overall function, aaRSs are divided into two classes on the basis of their catalytic domain, which binds ATP. While eukaryotic organisms contain at least twenty aaRSs, one enzyme for each amino acid, both bacterial and archaeal microorganisms might have less than the twenty enzymes since a few aminoacyl-tRNAs might be formed by an indirect pathway where a non-discriminating aaRS aminoacylates more than one tRNA with the same amino acid. A second enzyme (aminoacyl-tRNA reductases) completes the reaction transforming the noncognate attached amino acid into the corresponding cognate tRNA. ${ }^{[1]}$
All bacterial aaRSs have to be maintained at a critical level to ensure growth of microorganisms at a suitable rate depending on the supply of nutrients. Regulation of aaRSs gene expression is crucial to maintain cell fitness and growth, consequently, a variety of regulatory mechanisms that finely tune the level of aaRSs have been described.

In Escherichia coli, each synthetase gene so far analyzed is independently regulated, using diverse regulatory mechanisms. Transcription attenuation for the operon encoding the two subunits of PheRS, autogenous translation control by binding of ThrRS to the leader thrS mRNA and autogenous transcriptional control by binding of AlaRS to the promoter region of alas are the most well known mechanisms studied. [2]

In contrast, in Bacillus subtilis a T-box riboswitch mechanism, common for almost all aaRSs genes, has been described. ${ }^{[3,4]}$ The T-box system was initially uncovered by the analysis of the $B$. subtilis tyrs gene, which encodes a 
tyrosyl-tRNA synthetase (TyrRS) ${ }^{[5]}$ and extended to tyrZ, a gene encoding a second tyrosyl-tRNA synthetase (TyrRZ) in this bacterium. ${ }^{[6]}$ Here, alternative secondary structures upstream of the regulated coding sequence, that switch between a terminator and an anti-terminator of transcription, are induced based on the ratio of the charged/uncharged cognate tRNA. Although it is a general mechanism, it provides a specific response to each cognate amino acid starvation. The specificity of the response relies on the interaction between the tRNA anticodon and the specifier sequence (corresponding to a codon that matches the amino acid specificity of the downstream gene) within the leader region of the mRNA. Almost all T-box riboswitches studied to date regulate the expression of the corresponding gene at the level of transcription attenuation, with the exception of a T-box in Actinobacteria recently described, whose target is regulated at the translational level by blocking/deblocking the accessibility of the Shine-Dalgarno (SD) sequence in the mRNA to the ribosome. ${ }^{[7]}$ The T-box mechanism is mostly present in Gram-positive bacteria and, although less common, by comparative genomic analysis it has been identified also in Gram-negative microorganisms. ${ }^{[8,9]}$

Acidithiobacillus ferrooxidans is an acidophilic, Gram-negative, autotrophic, chemolithotrophic, facultative aerobic bacterium that participate in either natural or human-made bioleaching processes.[10,11] Its chemolithotrophy derives from its capacity to oxidize ferrous ions as well as reduced sulfur compounds as the source of electrons for the respiratory chains. This feature predicted that $A$. ferrooxidans would be an excellent model to study the biological processes involved in bioleaching of minerals. Important efforts have been made to understand the physiology, biochemistry and genetics of $A$. ferrooxidans as a model of the events that give rise to the industrial process and to find ways to improve it. Unfortunately, the genetic systems that have been developed for $A$. ferrooxidans are very fastidious.

The genome sequences of two $A$. ferrooxidans strains are available in public databases (ATCC $23270^{\top}$ and ATCC 53993 strains). From these data, prediction of a number of genes involved in the bioleaching process has been made. ${ }^{[11]}$ In addition, it has revealed that two large mobile genetic elements, ${ }^{[12,13]}$ together with insertion sequence elements, transposons and plasmids, ${ }^{[11,14,15]}$ have tailored the genome of $A$. ferrooxidans eventually by horizontal gene transfer (HGT). Furthermore, a gene encoding for a functional tyrosyl-tRNA synthetase with higher similarity to the $t y r Z$ gene product from $B$. subtilis than $E$. coli tyrS (44\% versus $24 \%$ identity, respectively) was identified. ${ }^{[16]}$ Similar to $B$. subtilis, A. ferrooxidans tyr $Z$ mRNA contains a 5 '-untranslated (leader) region that could have a role in its transcriptional regulation.
In order to analyze the possibility that the structural similarity between the product of $\operatorname{tyr} Z$ from $B$. subtilis and A. ferrooxidans extends to the regulation of its expression, we studied the mechanism that regulates the expression of A. ferrooxidans tyrz. Our results may contribute with additional knowledge, not only to the hypothesized HGT of structural genes, but also to the adaptation of regulatory mechanisms of gene expression between Gram-positive and negative bacteria.

\section{EXPERIMENTAL PROCEDURES}

\section{Bacterial Strains, Media, and Growth Conditions}

A. ferrooxidans ATCC $23270^{\top}$ was grown aerobically at $30^{\circ} \mathrm{C}$ in modified $9 \mathrm{~K}$ medium ${ }^{[17]}$ supplemented with $120 \mathrm{mM}$ $\mathrm{FeSO}_{4} \times 7 \mathrm{H}_{2} \mathrm{O}(\mathrm{pH}$ 1.6). E. coli JM109 and JW2581 (tyrA) were grown aerobically at $37^{\circ} \mathrm{C}$ in Luria-Bertani (LB) broth or LB agar (1.5\% $(w / v)$ agar) medium. E. coli JW2581 was also grown in $56 / 2$ minimal media ${ }^{[18]}$ supplemented with glucose. When necessary, the media was supplemented with $50 \mu \mathrm{g} \mathrm{mL}-1$ amino acids, $100 \mu \mathrm{g} \mathrm{mL}-1$ ampicillin and $50 \mu \mathrm{g} \mathrm{mL} \mathrm{L}^{-1}$ kanamycin.

\section{Analysis of Nucleotide Sequences}

All nucleotide sequences were obtained from the NCBI database and analysed by BLAST program. ${ }^{[19]}$ The secondary structure of the tyrZ RNA leader was predicted by RNA Fold using the PC/Gene software.

\section{RNA-Seq}

Total RNA from A. ferrooxidans ATCC $23270^{\top}$ was isolated from cells grown in $9 \mathrm{~K}$ medium supplemented with $\mathrm{Fe}^{2+}$ using the RNeasy Mini Kit (Qiagen) followed by a DNase I (Roche) treatment to eliminate DNA contamination. Ribosomal RNA was eliminated using the MICROBExpress kit (Ambion) following the manufacturer instructions. Libraries for Illumina sequencing were generated according to the mRNA Sequencing Sample preparation guide (Illumina-Solexa). 36-nt single-end reads were generated on a Solexa Genome Analyzer at the Molecular and Cellular Imaging Center (Ohio State University, Columbus, United States). The reads were analyzed using bioinformatic tools according to the following protocol: a total of 24,978,516 reads were generated from the RNA sample. The Solexa RNA sequencing dataset was filtered by eliminating lowquality reads. Data filtering was performed using Q-Solexa algorithm (score $=-10 \log 10(p /(1-p)))$ and clean reads sized at $36 \mathrm{nt}$ were collected for further analysis. These reads were aligned to the A. ferrooxidans ATCC $23270^{\top}$ reference genome obtained from the NCBI GenBank annotation (NC_011761) using the BLASTn program ${ }^{[19]}$ with 
default settings, except for the following modifications: an aligned read required a minimum of 15 nucleotides in length (coverage $\geq 70 \%$ ).

Fusions to lacZ pUJ9 vector ${ }^{[20]}$ was used to create gene fusions of tyrZ leader fragments to a promoter-less truncated 'lacZ gene. Using $A$. ferrooxidans ATCC $23270^{\top}$ genomic DNA as a template, the inserts were generated by PCR with Pfu DNA Polymerase (Stratagene) and the primers listed in Table 1. A 'lacZ fusion of the tyrZ promoter (pTyrZp) was generated with the primer pair pTyrZ1/pTyrZp. The construct pTyrZ containing the promoter plus the entire tyrz leader was generated with the primer pair pTyrZ1 / pTyrZ-1. The construct pTyrZ-t corresponding to the promoter plus the tyrZ leader region containing a deletion of the putative terminator sequence was generated using the primer pair pTyrZ1/pTyrZ-2. For both pTyrZp and pTyrZ-t the reverse primers include in their $5^{\prime}$ end the original SD sequence and the ATG start codon from the $E$. coli lacZ gene.

PCR products treated with T4 polynucleotide kinase were ligated to pUJ9 previously digested with Smal and treated with alkaline phosphatase FastAP (all enzymes from Fermentas). Blunt-end ligation reactions were carried at 16 ${ }^{\circ} \mathrm{C}$ overnight using concentrated T4 DNA ligase $(2,000,000$ units $/ \mathrm{mL}$, New England Biolabs). E. coli JM109 cells were transformed with the ligation products and the positive clones were checked by plasmid extraction and sequencing (Macrogen, USA).

\section{$\beta$-Galactosidase Assays}

E. coli JW2581 cells harboring 'lacZ fusions were grown until early exponential phase in LB broth. Cells were harvested and resuspended in fresh 56/2 minimal media supplemented or not with $50 \mu \mathrm{g} \mathrm{mL} \mathrm{m}^{-1}$ tyrosine or phenylalanine (Sigma). Samples were collected after $3 \mathrm{~h}$ of incubation at $37{ }^{\circ} \mathrm{C}$ with agitation, permeabilized by chloroform, and assayed as described in [21].
Table 1. Oligonucleotide primers used in this work.

\begin{tabular}{|c|c|c|}
\hline Primer & Sequence ${ }^{(a)}$ & Use \\
\hline pTyrZ1 & CGGATCGCTGGGACATACAT & $\begin{array}{l}\text { Primer forward used } \\
\text { for all lac } Z \text { gene } \\
\text { fusion constructs }\end{array}$ \\
\hline pTyrZp & $\begin{array}{c}\text { CATAGCTGTTTCCTCGCACCAA } \\
\text { AAAAACATTG }\end{array}$ & $\begin{array}{l}\text { Primer reverse to } \\
\text { generate the } \\
\text { construct PTyrZp }\end{array}$ \\
\hline pTyrz-1 & CATAAATTGGCCGGTGTCTTGTG & $\begin{array}{l}\text { Primer reverse to } \\
\text { generate the } \\
\text { construct PTyrz }\end{array}$ \\
\hline pTyrz-2 & $\begin{array}{c}\text { CATAGCTGTTTCCTGTGTAGAC } \\
\text { CATCGTCGCCAGGAG }\end{array}$ & $\begin{array}{l}\text { Primer reverse to } \\
\text { generate the } \\
\text { construct PTyrz-t }\end{array}$ \\
\hline $\begin{array}{l}\text { PMLB1034- } \\
\text { amp-F }\end{array}$ & GTGCCACCTGACGTCTAAG & $\begin{array}{l}\text { Sequencing primer } \\
\text { for pUJg }\end{array}$ \\
\hline $\begin{array}{l}\text { PMLB1034- } \\
\text { lacZ-R }\end{array}$ & CTGCAAGGCGATTAAGTTGG & $\begin{array}{l}\text { Sequencing primer } \\
\text { for pUJg }\end{array}$ \\
\hline
\end{tabular}

\section{RESULTS AND DISCUSSION}

\section{tyrZ Transcript Has a Leader Region With a Riboswitch-Like Element}

A. ferrooxidans ATCC $23270^{\top}$ tyr $Z$ is encoded downstream a hypothetical protein coding gene (AFE_RS14155) and upstream the rrnT2 rRNA operon (the first gene encodes the 16 S ribosomal RNA, rrsA; AFE_RS14145) (Figure 1). According to primer extension experiments, the tyrZ mRNA contains a 356 bp $5^{\prime}$-untranslated (leader) region ${ }^{[16]}$ (Figure 1 and S1, Supporting Information), as in tyrZ mRNAs from B. subtilis and other Gram-positive bacteria. In addition, the specific

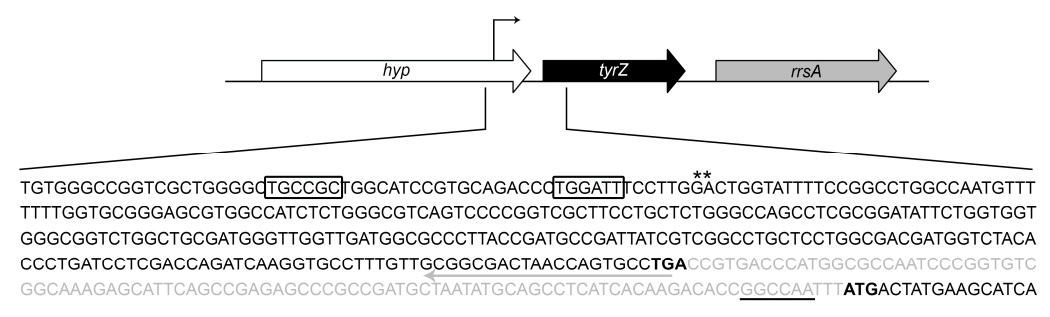

Figure 1. A. ferrooxidans ATCC $23270^{\top}$ tyrZ genetic organization and transcription/translation signals. The diagram is shown in the direction of tyrZ transcription. tyrZ gene is highlighted by a black arrow; its upstream (an hypothetical protein encoding gene, AFE_RS14155) and downstream (16S ribosomal RNA gene; AFE_RS14145) genes are depicted by white and gray arrows, respectively. Below it is shown the detailed sequence covering the tyr $Z$ transcription/translation signals (from $n t 2,772,788$ to $2,773,216$, complementary strand; GenBank Accession number NC_011761). The putative $\sigma^{70}$ tyr $Z$ promoter is depicted by a black arrow above the diagram, and by boxes on the detailed sequence below. The TSS identified by primer extension is depicted by asterisks, and the probe used is represented as a grey arrow below the sequence that hybridizes. The stop codon of the upstream gene and tyrZ start codon are in bold and the putative SD sequence is underlined. Intergenic sequence is shown in gray. 
activity of $A$. ferrooxidans TyrRZ in cells treated with tyrosine hydroxamate, which creates an artificial tyrosine starvation condition, increased 6 to 7 times when compared to cells grown in the presence of tyrosine (Figure $\mathrm{S} 2, \mathrm{SI}$ ).
Figure 2. Secondary structure model of $A$. ferrooxidans tyr $Z$ mRNA leader region. The putative specifier (UAC) and the T-Box sequence appears highlighted in white and grey circles, respectively. The structural model of the antiterminator conformation is shown; the alternative terminator conformation is shown in the box. The structure shown covers the corresponding DNA sequence from nucleotide 2,773,161 to 2,772,907 of the A. ferrooxidans ATCC $23270^{\top}$ genome. The site where the terminator deletion took place to create the pTyrz-t construct is indicated by a black arrowhead.
To test the hypothesis that the regulatory mechanism of TyrRZ expression is also conserved as the coding sequence, we predicted the secondary structure of the leader region of tyrZ mRNA.

The following structural elements were predicted: a Rho-independent transcription terminator, a 18 nucleotides sequence upstream of the terminator similar to T-box sequences of aaRS genes from Gram-positive bacteria, and a large stem that includes a codon for tyrosine (codon UAC) which could represent the specifier sequence (Figure 2). The tyrZ leader region resembles the glyQS leader RNA from $B$. subtilis since it lacks the complex stem II and stem IIA / B pseudoknot elements present in tyrZ leader RNA (Figure 2). The predicted putative T-box sequence has 11 out the 18 conserved residues of the described consensus sequence ${ }^{[5]}$ (Figure S3, SI). This sequence also contains four free nucleotides (5'-UGGU-3'), forming part of a bulb, which have been described important to base-pairing at the $3^{\prime}$ end of the cognate tRNA and stabilize the antitermination helix. All these conserved elements are important for the function of this type of riboswitches. Thus, the leader region of tyrZ exhibits some of the sequence features of tRNA-mediated T-box riboswitch systems, in spite of the lack of important structural characteristics as we mentioned above.

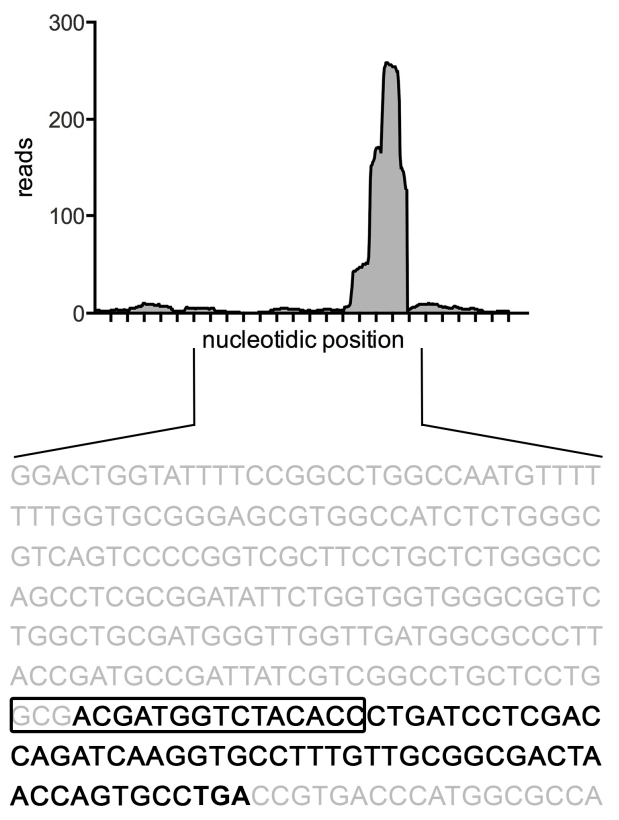

Figure 3. RNA-Seq reads distribution in the region involving the leader tyrZ region. The region with higher reads in the upper graph is shown in black and bold in the detailed sequence shown below (covering the region from $\mathrm{nt} 2,772$, 886 to $2,773,161$, complementary strand). The T-box sequence is shown in a box as reference. 


\section{TyrZ Leader Region from A. ferrooxidans Exhibits a Region With High Transcription Levels}

To elucidate whether there is a termination/antitermination activity in the tyrZ leader region, we analyzed the RNASeq transcriptomic data obtained from $A$. ferrooxidans grown in $9 \mathrm{~K}$ media supplemented with $\mathrm{Fe}^{2+}$, a standard laboratory growth condition. This analysis reveals that, in spite of a low expression level (reads number) in comparison to other $A$. ferrooxidans genes (data not shown), there is a transcript comprising part of the leader tyr $Z$ region and ending close to the terminator structure (Figure 3 ). This region covers approximately 70 nucleotides from position $2,772,972$ to $2,772,904$ in the genome. These data supported the assumption that there is a transcription termination mechanism working in the A. ferrooxidans tyr $Z$ leader region.

\section{A. ferrooxidans tyrZ Leader Region is Specifically Responsive to Tyrosine}

Riboswitches have been found to respond to a variety of metabolites (including amino acids and tRNAs) and to exert regulatory control of transcription, translation, splicing, and RNA stability. ${ }^{[22,23]}$ To analyze the functionality of the tyrZ leader region as a termination / antitermination riboswitch, the entire leader region (including the transcription promoter and terminator) as well as the leader region with a deletion of the terminator sequence, were cloned to create gene fusions to a promoter-less truncated 'lacZ gene. A construct carrying only the tyr $Z$ promoter fused to 'lac $Z$ was also included as a control. To check whether tyr $Z$ leader region responds to the presence of tyrosine, the different 'lac $Z$ fusions were introduced into E. coli JW2581, carrying a tyrA mutation that causes tyrosine auxotrophy. Bacteria containing different constructs were incubated in the presence or absence of Ltyrosine and the $\beta$-galactosidase activity of the cultures was measured. First, the functionality of the $\sigma^{70}$ promoter identified (Figure 1) was confirmed by assaying the 'lacz fusion containing only the promoter region (Figure $4 A$ ). The results showed that this promoter is active, and that its activity is similar in the presence or absence of tyrosine. However, when the construct containing the entire leader region was assayed, an increase in the $\beta$-galactosidase activity was obtained in the presence of tyrosine compared to the activity in the absence of the amino acid (Figure 4B). This suggests that no transcription termination is taking place at the tyrZ terminator within the leader mRNA in the presence of tyrosine. On the other hand, when the terminator sequence is removed from the $t y r Z$ leader region, the responsiveness to tyrosine was lost (Figure $4 B$, to compare pTyrZ versus pTyrZ-t). These results suggest that the deletion of the putative terminator sequence abolish the capacity of this predicted riboswitch to sense tyrosine.

This behavior could be explained in part due to the elimination of the ligand-bound or -sensor sites or by a conformational change that modified those sites (as these sites are still not identified we cannot rule out any alternative). Furthermore, this behavior was specific to tyrosine, since phenylalanine (also an aromatic amino acid) was unable to exert any effect on the $\beta$-galactosidase activity, even with the entire leader region (Figure $4 \mathrm{C}$ ).

The enzymatic activity of TyrRZ in A. ferrooxidans increased in the presence of the amino acid analog tyrosine hydroxamate, exerting an artificial tyrosine starvation
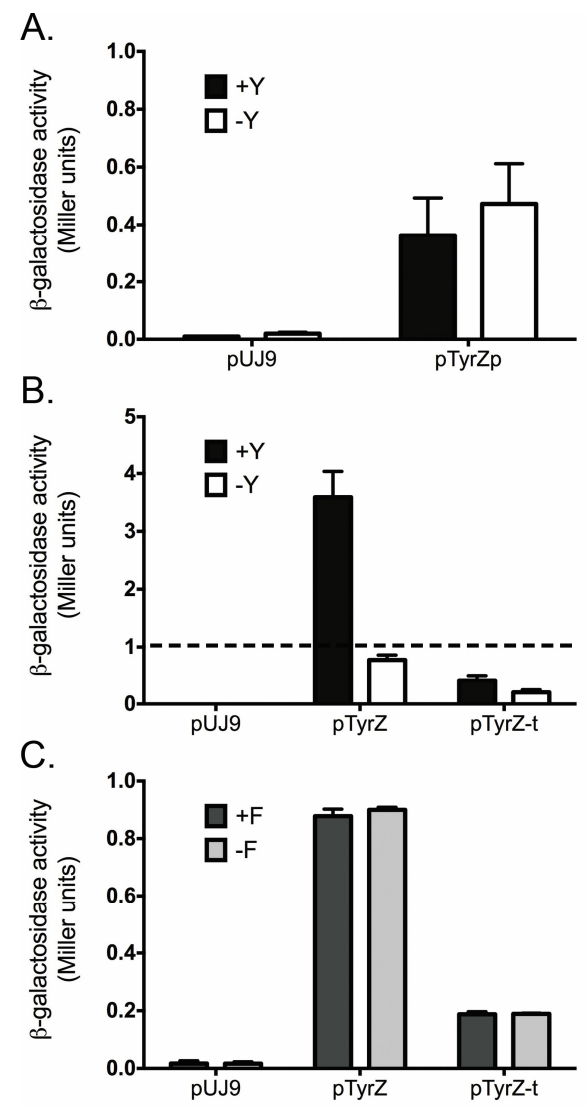

Figure 4. $\beta$-galactosidase assays of different tyrz leader fragments fused to lacZ. E. coli JW2581 harboring pUJ9 vector with gene fusions of the promoter region (pTyrZp), the entire leader region (pTyrz) or the leader region with a deletion of the terminator sequence ( $p$ Tyrz- $t$ ) were grown in minimal medium supplemented or not with tyrosine $(A$ and $B,+Y /-Y$, respectively) or phenylalanine $(C,+F /-F$, respectively) for $3 \mathrm{~h}$ at $37^{\circ} \mathrm{C}$ and then the $\beta$-galactosidase activity was measured. pUJ9 represents the empty vector. The broken line in B represents the upper limit plotted in A and $C$ for comparison. The means and standard deviation of three different experiments are plotted. 
(Figure S2, SI). According to the reported function of the T-box dependent tyrZ riboswitch from $B$. subtilis, if an excess of tyrosine is provided, transcription termination within the leader of tyrZ mRNA is expected. Surprisingly, the response of $A$. ferrooxidans leader tyr $Z$ mRNA in the presence of tyrosine (measured in the heterologous bacterium E. coli) was the opposite. While in the absence of tyrosine, the activity of $\beta$-galactosidase (a measure of transcription antitermination) was barely above the control, in the presence of the amino acid, 3-4 fold more activity was observed. Thus, presumably the amino acid induced the formation of the antiterminator secondary structure in the leader tyrZ mRNA. The functionality of the $A$. ferrooxidans tyr $Z$ leader region cannot be explained by the classical T-box mechanism, like that regulating the $B$. subtilis tyrosyl-tRNA synthetases. ${ }^{[5,6]}$ Alternatively, a direct sensing of the amino acid by the tyrZ riboswitch, instead of the aminoacyl-tRNA as in the T-box mechanism, could explain the $\beta$-galactosidase assay results. As $A$. ferrooxidans is an autotrophic microorganism naturally growing at a slow rate in environments with low organic matter, provision of amino acids, particularly tyrosine, must be low. Thus, low levels of TyrRZ would be sufficient to account for the required translation demands. That explains the weak tyrZ promoter activity detected under our experimental conditions, either by RNA-Seq (Figure 3), as well as lacZ fusions (Figure 4A).

In the case of an additional provision of tyrosine it can be hypothesized that an increase in cellular levels of TyrRZ would be required to account for the elevated amino acid availability. Thus, in our experiments we obtained an increase in $\beta$-galactosidase activity when the entire leader region was assayed in the presence of tyrosine (Figure 4B).

On the other hand, the tyrosine hydroxamate used to generate the artificial tyrosine starvation condition in $A$. ferrooxidans (Figure S2, SI) acts as a competitive inhibitor of TyrRZ, and consequently the enzyme cannot use the amino acid to aminoacylate the tRNA. This situation could generate an increase in tyrosine cellular levels and therefore in tyr $Z$ transcription.

If this is the mechanism that accounts for the induction of TyrRZ expression, it could be hypothesized that tyrosine hydroxamate could also be a ligand for the riboswitch that prevents the transcription termination by inducing the formation of the antitermination structure. These interpretations are coherent with the data obtained in this work using a heterologous bacterium. However, an additional unknown mechanism must be involved in the $A$. ferrooxidans tyr $Z$ transcriptional regulation to explain the higher $\beta$-galactosidase activity (9-10 fold) obtained in the presence of tyrosine with the entire tyr $Z$ leader region, in comparison to the basal promoter activity (Figure 4, to compare $\mathrm{A}$ and $\mathrm{B}$ ). We also must to consider that the constructs pTyrZp and pTyrZ-t contain lacZ SD, on the contrary pTyrZ contains tyrZ SD and as these constructs could have different translation efficiencies, that could have affected the $\beta$-galactosidase activities that we have recorded.

Whether this riboswitch uses as ligand and signal molecule the amino acid tyrosine, the uncharged tRNA ${ }^{\text {Tyr }}$ or the Tyr-tRNA ${ }^{\text {Tyr }}$, still needs to be elucidated.

Evolution of T-box ribowitches to acquire novel functions or transforming them to translation controlling systems have been documented. ${ }^{[9]}$ Despite this dynamic, every case reported seems to perform the same signaling function based on the ratio charged/ uncharged cognate tRNA. An increase of this ratio would prevent the expression of the structural gene by the formation of the transcription terminator (or the SD sequestrator).

Studies of the elements involved in translation machinery of $A$. ferrooxidans have revealed that some of them could have been acquired by HGT. Two genes encoding glutamyl-tRNA synthetases with different properties are encoded in its genome. ${ }^{[24-27]}$ As in the case of TyrRZ, one of these enzymes is closely related to B. subtilis GluRS both at the amino acid sequence as well as genomic organization. ${ }^{[27]}$

The system predicted in this report, which require experimental validation, suggests that TyrRZ may have been acquired by $A$. ferrooxidans from a Gram-positive bacterium together with its expression regulatory mechanism. But, once in A. ferrooxidans it would have evolved to a system where the opposite effect is exerted at the level of alternative transcription termination/antiterminator, more appropriate for an autotrophic microorganism growing in environments with low supply of organic matter.

Acknowledgment. This work was supported by grants from Fondecyt Chile 1110203 and 1150834 to $\mathrm{OO}$ and Universidad de Chile.

Supplementary Information. Supporting information to the paper is enclosed to the electronic version of the article at: http://dx.doi.org/10.5562/cca2832.

\section{REFERENCES}

[1] T. J. Bullwinkle, M. Ibba, Top. Curr. Chem. 2014, 344, 43.

[2] T. M. Henkin, The Aminoacyl-tRNA Synthetases, (Eds: M. Ibba, C. Francklyn, S. Cusack), Landes Bioscience, 2004, pp. 309-313.

[3] N. J. Green, F. J. Grundy, T. M. Henkin, FEBS Lett. 2010, 584, 318.

[4] T. M. Henkin, F. J. Grundy, Cold Spring Harbor Symp. Quant. Biol. 2006, 71, 231. 
[5] T. M. Henkin, B. L. Glass, F. J. Grundy, J. Bacteriol. 1992, 174, 1299.

[6] R. N. Williams-Wagner, F. J. Grundy, M. Raina, M. Ibba, T. M. Henkin, J. Bacteriol. 2015, 197, 1624.

[7] A. V. Sherwood, F. J. Grundy, T. M. Henkin, Proc. Natl. Acad. Sci. U. S. A. 2015, 112, 1113.

[8] A. Gutierrez-Preciado, T. M. Henkin, F. J. Grundy, C. Yanofsky, E. Merino, Microbiol. Mol. Biol. Rev. 2009, 73, 36.

[9] A. G. Vitreschak, A. A. Mironov, V. A. Lyubetsky, M. S. Gelfand, RNA 2008, 14, 717.

[10] V. Bonnefoy and D. S. Holmes, Environ. Microbiol. 2012, 14, 1597.

[11] J. Valdes, I. Pedroso, R. Quatrini, R. J. Dodson, H. Tettelin, R. $2^{\text {nd }}$ Blake, J. A. Eisen, D. S. Holmes, $B M C$ Genomics 2008, 9, 597.

[12] P. Bustamante, P. C. Covarrubias, G. Levicán, A. Katz, P. Tapia, D. Holmes, R. Quatrini, O. Orellana, J. Mol. Microbiol. Biotechnol. 2012, 22, 399.

[13] L. H. Orellana, C. A. Jerez, Appl. Microbiol. Biotechnol. 2011, 92, 761.

[14] D. S. Holmes, H. L. Zhao, G. Levican, J. Ratouchniak, V. Bonnefoy, P. Varela, E. Jedlicki, J. Bacteriol. 2001, 183, 4323.

[15] J. C. Oppon, R. J. Sarnovsky, N. L. Craig, D. E. Rawlings, J. Bacteriol. 1998, 180, 3007.
[16] O. Salazar, B. Sagredo, E. Jedlicki, D. Söll, I. WeygandDurasevic, O. Orellana, J. Bacteriol. 1994, 176, 4409.

[17] M. P. Silverman, D. G. Lundgren, J. Bacteriol. 1959, $77,642$.

[18] B. Low, J. Bacteriol. 1973, 113, 798.

[19] C. Camacho, G. Coulouris, V. Avagyan, N. Ma, J. Papadopoulos, K. Bealer, T. L. Madden, BMC Bioinf. 2009, 10, 421.

[20] V. de Lorenzo, M. Herrero, U. Jakubzik, K. N. Timmis, J. Bacteriol. 1990, 172, 6568.

[21] J. H. Miller, Experiments in Molecular Genetics, Cold Spring Harbor Laboratory Press, Cold Spring Harbor, New York, 1972, pp 352-355.

[22] A. Serganov ,E. Nudler, Cell 2013, 152, 17.

[23] A. Serganov, D. J. Patel, Nat. Rev. Genet. 2007, 8, 776.

[24] C. Farah, G. Levican, M. Ibba, O. Orellana, Int. J. Mol. Sci. 2014, 15, 23011.

[25] A. Katz, R. Banerjee, M. de Armas, M. Ibba, O. Orellana, Biochem. Biophys. Res. Commun. 2010, 398, 51.

[26] G. Levican, A. Katz, M. de Armas, H. Nunez, O. Orellana, Proc. Natl. Acad. Sci. U. S. A. 2007, 104, 3135.

[27] H. Nunez, C. Lefimil, B. Min, D. Soll, O. Orellana, FEBS Lett. 2004, 557, 133. 


\section{SUPPORTING INFORMATION}

\section{SUPPORTING EXPERIMENTAL PROCEDURES}

\section{A. ferrooxidans growth conditions}

A. ferrooxidans ATCC $23270 \mathrm{~T}$ was grown aerobically at $30^{\circ} \mathrm{C}$ in tetrathionate medium $\left(\mathrm{Na}_{2} \mathrm{~S}_{4} \mathrm{O}_{6} 3,0 \mathrm{~g} / \mathrm{l}\right.$; $\left.\mathrm{KH}_{2} \mathrm{PO}_{4} 3,0 \mathrm{~g} / \mathrm{l} ;\left(\mathrm{NH}_{4}\right)_{2} \mathrm{SO}_{4} 3,0 \mathrm{~g} / \mathrm{l} ; \mathrm{MgSO}_{4} 0,5 \mathrm{~g} / \mathrm{l} ; \mathrm{CaCl}_{2} 0,5 \mathrm{~g} / \mathrm{l} ; \mathrm{pH}=3.5\right)$. To induce a tyrosine starvation condition, the bacteria were grown until mid log phase and washed twice with fresh medium. Resuspended cells were then inoculated in tetrathionate medium supplemented with $4 \mathrm{mM} \mathrm{L-tyrosine}$ (Sigma) (control culture) or $2 \mathrm{mM}$ tyrosine hydroxamate (Sigma) at a final concentration of $1 \times 10^{8}$ cells $/ \mathrm{ml}$. After incubation at $30^{\circ} \mathrm{C}$ for $22 \mathrm{~h}$ with agitation, cells were recovered by centrifugation.

\section{Primer extension assay}

$100 \mu \mathrm{g}$ of total RNA and 3-5 pmol of primer PETyrZ ([32P]-CAGGCACTGGTTAGTCGCCGC)

were precipitated with ethanol and resuspended in $10 \mu \mathrm{l}$ of buffer $\mathrm{A}(50 \mathrm{mM}$ Tris- $\mathrm{HCl}(\mathrm{pH}=8.3), 6 \mathrm{mM}$ $\mathrm{MgCl}_{2}, 100 \mathrm{mM} \mathrm{KCl}$ ). Samples were incubated $10 \mathrm{~min}$ at $85^{\circ} \mathrm{C}$ followed by $2 \mathrm{~h}$ at $50{ }^{\circ} \mathrm{C}$ to allow primer hybridization. cDNA synthesis reaction was carried at $37^{\circ} \mathrm{C}$ for $1 \mathrm{~h}$ in $20 \mu \mathrm{l}$ of buffer $\mathrm{A}$ containing $5 \mathrm{mM}$ $\mathrm{DTT}, 1 \mathrm{mM}$ of each dNTP, $20 \mathrm{U}$ RNase inhibitor and $5 \mathrm{U}$ AMV reverse transcriptase. After this step 20 $\mu \mathrm{g}$ RNase $\mathrm{A}$ were added to the reaction followed by incubation at $37^{\circ} \mathrm{C}$ for $15 \mathrm{~min}$. Nucleic acids were extracted by phenol:chloroform, precipitated with ethanol in the presence of $1 \mu \mathrm{g}$ salmon sperm DNA and resuspended in $6 \mu \mathrm{l} \mathrm{TE}$ buffer. $4 \mu \mathrm{l}$ of loading buffer ( $80 \%$ formamide, $10 \mathrm{mM}$ EDTA pH = 8.0, 1 $\mathrm{mg} / \mathrm{ml}$ xylene cyanol, $1 \mathrm{mg} / \mathrm{ml}$ bromophenol blue) were added to the samples and analyzed by denaturing urea PAGE in a $6 \%$ polyacrylamide gel containing $8 \mathrm{M}$ urea.

\section{Enzymatic activity of TyrRZ}

TyrRZ enzymatic activity was measurement as an in vitro charging activity as described in Ref. 16 


\section{SUPPORTING LEGENDS}

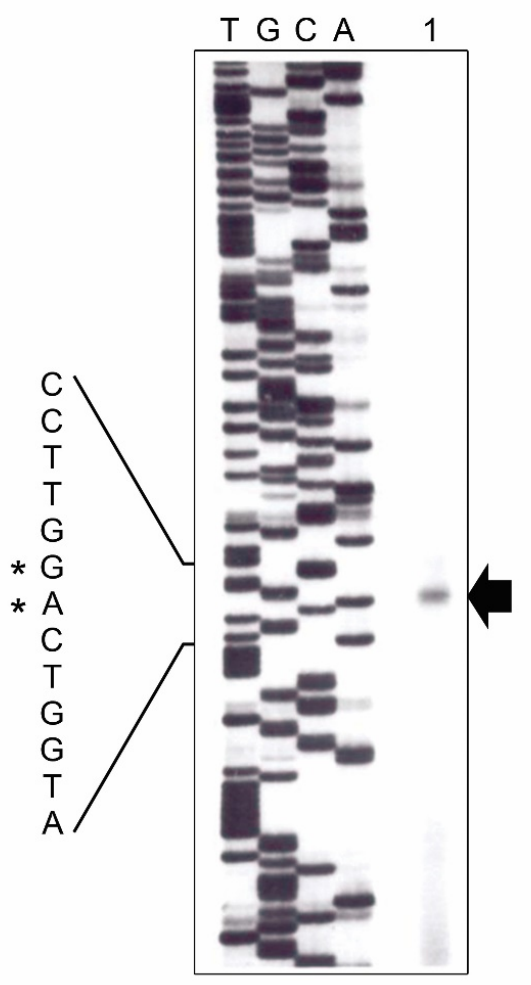

Figure S1. Determination of the transcription start site (TSS) of tyrZ by primer extension. The primer PETyrZ ([32P]-CAGGCACTGGTTAGTCGCCGC) that hybridizes between nt 2,772,905 and 2,772,925 was used as probe.

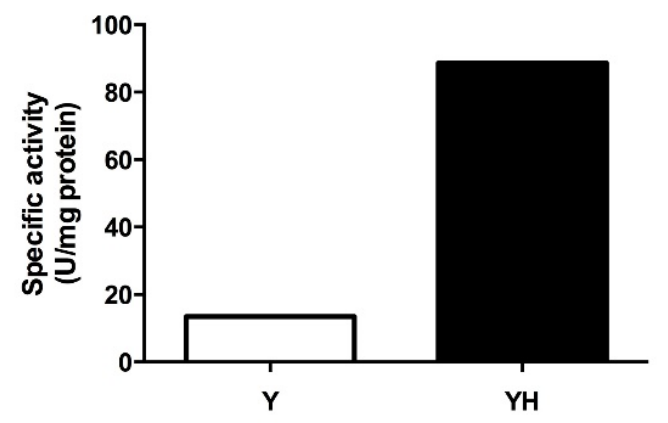

Figure S2. Enzymatic activity of TyrRZ under starvation conditions. The bacteria (previously adapted to growth in the presence of tyrosine) were grown in tetrathionate medium until mid log phase and then transferred to tetrathionate medium supplemented with $4 \mathrm{mM}$ tyrosine $(\mathrm{Y})$ or $2 \mathrm{mM}$ tyrosine hydroxamate $(\mathrm{YH})$, and incubated at $30^{\circ} \mathrm{C}$ for $22 \mathrm{~h}$ with agitation. Then cell extracts were prepared and the TyrRZ specific activity was measured.

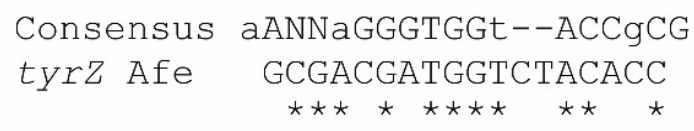

Figure S3. Nucleotide comparison of the putative $A$. ferrooxidans tyrZ T-box sequence with the T-box consensus. Conserved nucleotides are indicated by asterisks. 